Rasim M. Alguliyev' ${ }^{1}$, Rasim Sh. Mahmudov ${ }^{2}$

${ }^{1,2}$ Institute of Information Technology ANAS, Baku, Azerbaijan

DOI: $10.25045 /$ jpis.v08.i1.11

${ }^{1}$ secretary@iit.ab.az, ${ }^{2}$ rasimmahmudov@gmail.com

\title{
THE ROLE AND PROSPECTS OF INFORMATION AND COMMUNICATION TECHNOLOGIES IN THE INTEGRATION OF SCIENCE AND EDUCATION
}

The article examines the capabilities of ICT in the integration of education and science. Furthermore, transformation of scientific knowledge in the education process, solutions to problems associated with the use of new educational models based on ICT opportunities are analyzed and displayed. The necessity of training of cyber soldiers to secure the country's information space is justified. The paper also makes proposals for efficient use of capabilities of the science-computer network AzScienceNet combining all scientific institutions and organizations of ANAS in a single infrastructure for the integration of science and education in Azerbaijan.

Keywords: integration of science and education, uninterrupted education, distance education, cybersoldier, AzScienceNet.

\section{Introduction}

Science and education are the main driving forces of community. Science and education has always been in close contact with each other at all stages of civilization. Because, these areas cannot separately develop or achieve any success. Successful scientific achievements, new discoveries and inventions urge making changes in the curriculums and developing new educational technologies. Moreover, new knowledge is added to the content of education, and new disciplines are included to the curriculum. Scientific innovation has an impact on all levels of education.

The education system, in turn, serves as a social practice and tool for the transfer, dissemination and application of scientific knowledge. At the same time, the education system plays a role of the social environment for training future scientists.

Though, there has been always a mutual cooperation between science and education, traditional relations historically formed between these two strategic areas do not meet the requirements of today and the development specifications. Therefore, the development and implementation of new methods and mechanisms for new interaction and integration processes between these strategic areas is the demand of the modern time.

The integration of science and education in the modern era should become a mutually beneficial process, thus the both parties could equally take advantage, and as a result, the formation of a unified scientific and educational environment to be ensured. Legal, political, economic, technological, and organizational aspects of the integration of modern scientific and educational systems can be distinguished.

The integrative development of science and education is of particular importance in the information society. Hence, in this new stage of the civilization, information and knowledge are becoming a key material wealth and the most important strategic product. The main manufacturers of these products are the scientific and educational systems. Information and communication technology (ICT), which is the main driving force of the information society, has also great potential and prospects to ensure successful and sustainable integration of science and education.

\section{The issues of transformation of scientific knowledge to the education}

Currently, revolutionary processes are observed in the areas of scientific research under the influence of ICT [1]. As a result of the dynamic development of scientific and technical progress, new scientific and high-tech knowledge is rapidly emerging. Since, each knowledge area, in essence, is the process of data processing, the penetration of ICT into this environment is inevitable 
(the process of informatization of science is going on), accordingly, new multidisciplinary knowledge areas are emerging (Figure 1):
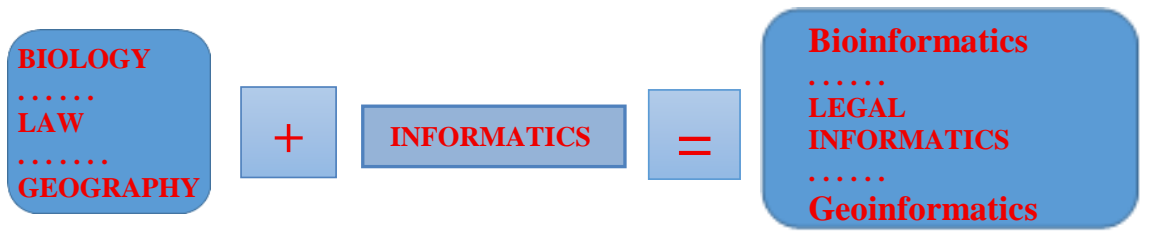

Figure 1. Multidisciplinary knowledge areas

Moreover, in recent years, a new multidisciplinary scientific field, namely DATA SCIENCE has emerged with the introduction of ICT in different fields of knowledge. This science ensures to get deeper knowledge as a result of involving mathematical methods to the processing BIG DATA (Figure 2):

\section{The formula for the XXI century science = KNOWLEDGE AREA - INFORMATICS - MATHEMATICS}

Figure 2. Multidisciplinary scientific fields

In addition, one of the main tasks of science and education in the modern era is to train the builders of the information society. To this end, it is necessary to form a potential of human resources in all multidisciplinary spheres of human activity, which are formed in on-line environments (right to information, information economy, information, culture, etc.).

The knowledge in some specialties is updated very rapidly and outdated almost with the same pace (in particular, ICT knowledge). The teachers acting in the educational system (especially, multidisciplinary areas) face massive difficulties in acquiring new knowledge.

However, the officials in charge of higher education institutions do not tend to open new disciplines and train new subjects in the new areas of knowledge so much. This is due to the lack of tutors teaching those new subjects, textbooks and other necessary material and technical basis. For this reason, it is not possible to train cadres on numerous multidisciplinary knowledge areas (e.g., software engineering, bioinformatics, Data Science, cryptography, etc.), which are of strategic importance for the development of Azerbaijan.

To overcome the above mentioned problems and to adapt to the rapid pace of technological development, the educational system should be regularly provided with new knowledge. Furthermore, newly obtained knowledge must be transformed to the society through the educational system.

Given the challenges and demands of the modern era, it is important to pay special attention to the above-mentioned specialties when training highly qualified personnel. In particular, the youngsters should prefer priority specialties when going to study abroad within the state programs.

It should be noted that one of the challenges of the information society is the concept of uninterrupted education. Thus, in the information society, existing knowledge is rapidly outdated and replaced with new one. This is mainly due to the rapid development of the ICT. To ensure a continuous transformation of new knowledge into the education sector, it is significant to organize qualification courses for teachers in different subjects at leading scientific institutions of Azerbaijan.

Today, one of the most important issues to be implemented for the integration of science and education is the involvement of scientists and experts to the pedagogical activity, as well as of the teachers into the research. Acquiring the pedagogical, psychological knowledge and other necessary skills facilitates researchers to deliver obtained knowledge to the educational audiences more effectively. All of these ensure more flexible transfer of scientific advances and innovations 
to the educational process. This integrative process and eliminating the detachment between science and education leads to more intensive integration and ultimate unification of respective professional areas.

\section{Application issues of new educational models}

Due to the new opportunities created by the ICT, new paradigms, concepts, and models of education are emerging in the XXI century. All of these serve to adapting the education system to the requirements of information society and to the rapid pace of technological development and improve its quality [1].

People have opportunities to acquire scientific knowledge more effectively due to the opportunities of ICT, including the Internet. Hence, the process of continuous education is possible only in terms of close relations with the scientific environment, where ICT play the role of integrator.

However, the Internet supports the education, on the one hand, and causes great damage on the other hand. Thus, the richness and accessibility of information and knowledge resources on the Internet create great opportunities for the participants of the educational process. But, the abuse of these facilities has a negative impact on the process. Thus, instead of solving the tasks given by teacher, a learner does not acquire necessary knowledge retrieved from the ready Internet resources by presenting it as his/hers, but imitates it.

In other words, knowledge on the Internet can easily be accessed and stolen. Thus, plagiarism is turning into serious problem not only in the modern scientific activity, but also in the education system. Consequently, poor quality professionals are growing. Teachers, in turn, do not have all the testing and other necessities to assess the level of knowledge in such a situation. It also creates difficulties in the assessment of students' knowledge.

One of the basic education models in the information society is distance learning. Technological condition necessary for the formation of distance education is already provided in Azerbaijan. Therefore, the Internet infrastructure here has been expanded and improved. Including the most rural settlements of the country, entire territory, as well as the educational institutions have been provided with high quality Internet access. In other words, the digital divide has been eliminated. However the knowledge is erratically distributed. Knowledge and its carriers, namely scientists and specialists are mostly concentrated in the capital. The most effective way of eliminating this inequality is the use of ICT opportunities, including the use of distance education technologies. Although, the Internet infrastructure necessary for the application of distant education is available in Azerbaijan, a number of problems related to their introduction still exist: the lack of necessary content, training and assessment technologies, the identification of person, and so on delays the implementation of this process.

The state policy on the formation and development of e-education is available in Azerbaijan. "Azerbaijan 2020: look into the Future" Concept of Development, "National Strategy for the Development of information society in the Republic of Azerbaijan for 2014-2020", and the Strategic Road Map for the development of telecommunications and information technologies in the Republic of Azerbaijan also specify conceptual framework of e-learning [2 -4].

However, legal, organizational, technological, economic, psychological, ethical and other aspects of e-learning system have not been developed enough yet. To overcome the problem, it is also important to develop online educational technologies that have specific features and to train relevant personnel. It is necessary to produce on-line intellectual learning resources for the formation of distance and virtual education, as well as intellectual examination products to assess the knowledge.

In the context of the challenges and realities of the modern era (Internet-education, online education, continuing education, person-oriented education, etc.), the study of the problems facing pedagogical and other related sciences should be supported. 


\section{Building cyber-soldiers}

Along with and the sovereignty of the independent Azerbaijan, as well as its integral part, namely its political, economic, military and other sovereignties, the information sovereignty has also been strengthened and developed over the past 25 years, and the Virtual Azerbaijan with the same distance from the neighboring countries and nations of the world has been formed [5 ].

Today, Azerbaijan is experiencing the information war. Foreign countries and forces feeding the hostile attitude toward Azerbaijan are using information war tools against our country - through the spread of misinformation, attacks on web sites and so on. A number of leading countries are developing effective mechanisms and building cyber troops to timely prevent such attacks and to take preventive measures.

Existing realities dictate Azerbaijan to take appropriate steps either. The information war technologies and information weapons applied against Azerbaijan must be investigated and the actions must be taken against them. To be protected from the mentioned threats, the development of different types of cybertroops, technologies and information weapons grounding on the advanced international experience is the demand of modern time.

Along with traditional weapons, today's soldiers and officers should master high technology and become a cyber soldier, who is ready to fight in the information wars both in real and virtual space. It is no secret that the advanced countries have already set up their cybertroops.

We must be ready for Information warfare and shift to attacker position from waiting position, as well as to promote the realities of Azerbaijan and to protect its interests and national and spiritual values in the virtual world.

As the pupils and students learn how to use military equipment and fire weapons in the education process, they should also be educated the secrets of information warfare technologies, and be ready to fight the attacks against Azerbaijan and its people in the virtual space. They should be taught the necessary competences to efficiently operate with the Internet resources, social networks, Wikipedia and other sources.

Given the fact that information technology is developing rapidly, thus, the technological capabilities of the information war is also constantly expanding. Therefore, the process of training cybersoldiers requires close cooperation and integration of science and education. In other words, scientific innovations in the field of information warfare technology should be studied in a flexible manner, and directed to the development process of cyber soldiers. The need for ensuring the security of national information space increases the urgency of establishing such a mechanism.

The Institute of Information Technology of ANAS has been conducting scientific research on information security, information warfare technologies, as well as on Wikipedia for a long time, and has achieved significant results. The rich knowledge gained in these areas by the Institute is educated to all doctoral and $\mathrm{PhD}$ students from all over the country, and to the staff of research institutions and organizations of ANAS. The successful experience gained in the research institute can be applied in the education system. The Institute of Information Technology of ANAS, in turn, can provide the necessary scientific and methodological support to the educational institutions of the country.

\section{AzScienceNet as an important tool for integration of e-science and e-learning}

AzScienceNet science and computer network has a great potential in terms of the integration of science and education of Azerbaijan. This national operator on the science and education network provide research institutions and organizations of ANAS with advanced networking services necessary for the implementation of researches, scientific and practical and educational issues, as well as for the integration into the world science [6].

It should be noted that "Azerbaijan 2020: look into the Future" Concept of Development" [2], "National Strategy for the Development of science in the Republic of Azerbaijan for 2009-2015" [7] and "National Strategy for the Development of information society in the Republic 
of Azerbaijan for 2014-2020" [3] specify important duties, such as strengthening the information support of science, forming e-science and the use of ICT in the scientific activities.

In accordance with the tasks put against AzScienceNet, as the result of the implemented work done, at present, 97 percent of the units connected to the in the network is using the broadband Internet. The Internet connection speed of the network is $410 \mathrm{Mbit} / \mathrm{sec}$. Thus far, about 6,500 computers research institutions and organizations of ANAS have been connected to AzScienceNet. At the same time, technical capabilities of AzScienceNet have been expanded. At present, its computing power is 15 Tflops, and external memory capacity is 400 Tbyte [8].

As a continuation of this work, new Internet Services Centre of AzScienceNet has opened. This centre covers 26 research institutions and organizations and providers Internet services to about 4000 employees of the Academic Village, and is equipped with modern telecommunication equipment and software.

The center offers Wi-Fi, Eduroam, Cloud Computing, Cloud Storage, cluster computing, hosting, Eduroam, IP Telephony, distributed multi-terminal information service, operational informing, video conferencing, e-libraries, distance education and other services to the employees of ANAS. In addition to the institutions and organizations of ANAS, higher education institutions of Azerbaijan and other research organizations and individual users can take advantage of Cloud Computing services offered by AzScienceNet [8].

Recently, as a result of the ongoing reforms at ANAS, large amount of digital video, audio, photo and multimedia resources containing different aspects of the research and organizational activities have been collected. They are of historical importance as valuable sources reflecting the current activity of the Academy. Systematic and regular collection of these materials, their reliable storage, systematization, online use and delivering to the future generations is very important.

AzScienceNet also offer videoconferencing and distance learning services for the research and educational institutions in Nakhchivan and Ganja. In the nearest future, the relevant centers in Shaki and Lankaran are planned to be provide with these services.

Establishing close cooperation with the international organizations, AzScienceNet enables the employees of the institutions and organizations of ANAS to benefit from the opportunities offered by research and education networks around the world: scientists jointly use large volumes of data in their research, implement large-scale scientific projects, and present advanced networking technologies and services.

In 2014, AzScienceNet became a member of the Association of European Science and Education Networks (GEANT) as the national operator status with the support of ANAS, the Ministry of Education and the Ministry of Communications and High Technologies and established the cooperation with more than 40 countries. The main objective of the association is to establish high-quality ICT infrastructure for science and education, to form unique and global space for the national e-science and education, and to improve the national and international electronic infrastructures used for scientific purposes [8].

In 2016, AzScienceNet joined pan-European network initially with $1 \mathrm{~GB} / \mathrm{sec}$ speed within the framework of the project (EaPConnect) designed for the countries supporting European Commission's Eastern Partnership initiative and got a chance to use important network services (hosting, cloud computing, eduroam etc.).

The educational institutions of the country can take advantage of the services (hosting, cloud computing, eduroam etc.) offered by AzScienceNet and DATA Centre. Scientists living in Baku can deliver interactive distance courses to all higher education institutions, as well as to universities in the regions over AzScienceNet through on-line videoconferencing studios of ANAS. At the same time, the lectures data can be delivered on-line in the future being stored at the DATA center. 


\section{Conclusion}

The requirements to the integration of science and education are based on the challenges of the information society. At the present stage, there are multiple opportunities for the flexible and efficient use of achievements of information technology in science and education and to provide information support. These opportunities also influence the development of the bilateral relations of the society within these two main intellectual fields of activity and the improvement of their productivity. The integration between the scientific and educational spheres provides an important contribution to the development of the relevant fields, as a whole, to the establishment of an information society, the establishment of knowledge economy, and the provision of information security in Azerbaijan.

\section{References:}

1. Alguliyev R.M. One of the main goals of science and education is to educate the builders of the information society, http://ict.az/az/news/1991

2. "Azerbaijan 2020: Look into the Future" Concept of Development, December 29, 2012, http://www.president.az/files/future_az.pdf

3. "National Strategy for the Development of information society in the Republic of Azerbaijan for 2014-2020", April 2, 2014, http://president.az/articles/11312

4. Strategic Road Map for the development of telecommunications and information technologies in the Republic of Azerbaijan, December 6, 2016, http://www.president.az/articles/22382

5. "The need for the cybersoldiers in Azerbaijan" - Rasim Alguliyev, http://news.milli.az/country/501372.html

6. Alguliyev R.M. AzScienceNet has great potential in the integration of science and education in the country, http://www.science.gov.az/news/open/4959

7. "National Strategy for the Development of science in the Republic of Azerbaijan for 2009-2015”, http://www.mdi.gov.az/files/uploader/milli_strategiya.doc

8. Alakbarov R.G. AzScienceNet science-computer network: development stages, Internet services and prospects // Information Society Problems, 2016, No1, pp.12-22. 